\title{
"Natureza da ciência geográfica": diagnóstico e possibilidades de inserção de epistemologia no ensino escolar e na formação de professores de geografia
}

\section{"Nature of geographical science": diagnosis and possibilities of the insertion of epistemology in geography education in school and teacher training}

Dante F. Costa Reis Junior ${ }^{1}$. Barbara Mayanne Silva ${ }^{1}$. Evelyn L. Dias Figuereido ${ }^{2}$

Resumo: Ausente das discussões sobre ensino de ciência, a Geografia continua transmitindo ao grande público a imagem desabonadora de disciplina meramente descritiva e catalográfica. No entanto, dada a natureza de seu objeto (a interface complexa de fenômenos naturais e dinâmicas socioeconômicas), ela possui notável potencial para uma leitura do tipo epistemológica - fato que, normalmente, deveria oportunizar modalidades de ensino mais instigantes e elucidativas. Apresentamos um diagnóstico geral sobre o conteúdo veiculado em textos correntes sobre (e para) o ensino da Geografia, ressaltando a ainda discreta incorporação de temas associados à filosofia e à história da ciência.

Palavras-chave: Ensino de “NdC”. Epistemologia da geografia. Ensino de geografia.

\begin{abstract}
Absent from the discussions about science teaching, Geography continues to transmit to the general public the degrading image of a purely descriptive discipline, with a merely recording role. However, given the nature of its object (the complex interface of natural phenomena and socioeconomic dynamics), it has a remarkable potential for an epistemological type of reading - a fact that should normally give rise to more insightful and elucidating teaching modalities. We present a general diagnosis of the content of current texts on (and for) Geography teaching, highlighting the still minimal incorporation of themes associated with philosophy and the history of science.
\end{abstract}

Keywords: "NOS” teaching. Epistemology of geography. Geography teaching.

\footnotetext{
${ }^{1}$ Universidade de Brasília (UnB), Departamento de Geografia, Brasília, DF, Brasil. E-mail: < dantereis@unb.br>.

${ }^{2}$ UnB, Faculdade de Educação, Brasília, DF, Brasil.
} 


\section{Introdução: a natureza da pesquisa e a justificativa de sua relevância}

Há várias décadas, discussões didático-pedagógicas atraem a comunidade de geógrafos brasileiros. Fóruns de debate foram realizados, publicações coletivas vieram a público.

E se constata nos documentos resultantes, que se trata de um âmbito de investigação realmente bastante vasto. Como há de ocorrer na literatura sobre a didática de outras disciplinas, ele circunscreve tanto a família de temas relacionados com a perspectiva teórico-filosófica do ensino, quanto o espectro de questões mais atinentes ao ângulo operacional da prática docente. Nesse ponto, provavelmente, não divergem as publicações que abordam o ensino de Biologia, de Geografia ou de Literatura - se quisermos entender estas disciplinas como boas representantes das chamadas ciências naturais, ciências sociais e humanidades, respectivamente.

Contudo, em se tratando das segundas, no país é já longeva a tradição de pesquisas que, ostentando um particular viés político-ideológico, ressaltam, sobretudo, o que seus autores entendem serem distorções do sistema social, estrutura da qual derivariam toda sorte de mazelas associadas a conteúdo programático e à formação de professores. Referimo-nos a uma tendência tornada rígida desde, pelo menos, os anos 1980, e cujos produtos bibliográficos, altamente disseminados no Brasil, difundem um estilo de argumento discursivo que acaba, por efeito colateral, constrangendo a emergência de linhas investigativas mais plurais. Dentre elas, as que pretendam recuperar algo das leituras racionalista e pragmática, por exemplo.

Não se trata de censurar aquele viés, que, sem dúvida, a seu tempo, contribuiu imensamente para que o pensamento sobre o ensino fosse além dos elementos cognitivos da aprendizagem, apontando contradições da realidade social e fazendo ver a importância das microescalas do indivíduo, do lugar e dos valores culturais - ocultadas pelo discurso técnico. No entanto, um reducionismo substituiu o outro, e a nova hegemonia intimidou abordagens que poderiam salvar algo dos aspectos epistêmicos relacionados ao processo de produção do conhecimento (aspectos que, a exemplo dos fatores sociológicos, nunca deixaram de estar presentes).

Assim, os estudos de Ensino de Geografia no país vêm explorando questões relacionadas com renovação (assumindo que técnicas e procedimentos correntes mantêm-se conservadores e/ou alienantes) e criticismo (entendendo que, sem revisão profunda dos programas, os estudantes de Licenciatura não terão como livrar seus futuros alunos de um exercício maquinal de aprendizagem escolar). Não são visíveis os estudos preocupados em demonstrar a natureza cientifica da Geografia; estudos que pudessem explorar modalidades de demonstração didática sobre como, por exemplo, funciona o raciocínio inferencial do geógrafo. Uma reorientação temática que faria os estudantes perceberem a racionalidade envolvida no juízo geográfico sobre os fenômenos, além de (saudavelmente) estimular a aproximação dos pesquisadores de Ensino de Geografia de uma produção acadêmica mais ampla, sobre Didática de Ciência.

Mesmo porque nessa produção se constata uma notável convergência: reforçar programas de ensino com a introdução de temas de história e filosofia da ciência sana a superficialidade dos entendimentos sobre ciência, oportunizando, inclusive, melhor modo de assimilação dos conteúdos especializados de área, mediante sua reinterpretação pela ótica da teoria do conhecimento científico. Trata-se de uma forma de humanizar as ciências, demonstrando que não estão afastadas de interesses políticos, mas também de impelir os alunos a pensá-las em sua capacidade de gerar significados, auxiliando a assimilação dos conteúdos de sala de aula (MATTHEWS, 1995). Uma tal aposta metodológica pode servir de antídoto às operações 
mnemônicas tanto quanto pode familiarizar os jovens estudantes com a natureza poliédrica da produção do saber científico: ela é lógica porque as afirmações são avaliadas criteriosamente e é contextual, posto que se manifestam valores e retóricas, que agem à margem dos protocolos racionalistas (McGUIRE; TUCHANSKA, 2013; SILVA, 2009).

Recentemente, tomamos contato com estudos empreendidos por pesquisadores do Centro de Formación y Investigación en Enseñanza de las Ciencias (CeFIEC) lotado na Faculdade de Ciências Exatas e Naturais da Universidade de Buenos Aires, dirigido pelo professor doutor Agustín Adúriz-Bravo e que compreende, dentre outros, um grupo de investigação especialmente consagrado a estudos articulados de Didática e Epistemologia.

Inspirados nas pesquisas realizadas nesse polo sul-americano - em particular naquelas que examinam conteúdos veiculados em literatura pedagógica (AMADOR-RODRÍGUEZ; ADÚRIZ-BRAVO, 2012) -, executamos, na Universidade de Brasilia, um projeto de pesquisa enquadrado na área de Ensino de Geografia. Porém, difere-se dos estudos dominantes, na medida em que pretendíamos rastrear tópicos que estão além da fronteira da Geografia, e com a pretensão de vir a conceber modos de replicá-los para o caso geográfico.

Os cursos de formação de professores em Geografia ressentem-se de literatura e abordagens de questões relacionadas com a natureza da ciência (ou NOS, de nature of science, acrônimo já consagrado entre especialistas, que doravante substituiremos por $\mathrm{NdC}$ ). Tópicos inscritos, por exemplo, no quadro de matérias da Filosofia da Ciência. Como se depreende, resulta dessa lacuna que as Licenciaturas apenas excepcionalmente preverão em seus programas disciplinas que conduzem a um exame detido sobre os contornos identitários do pensamento e da prática científicos, isto é, mais além da suposta identidade peculiar do pensamento e prática geográficos (crença cultivada entre muitos pesquisadores da Geografia, e que acaba os desviando de incursões junto a círculos mais ecumênicos). Intrigados com esse fato, nos sentimos motivados

\footnotetext{
${ }^{3}$ Por natureza da ciência compreende-se o conjunto de fatores que caracterizam tanto a elaboração, quanto a organização do conhecimento e da prática científicos. Tais fatores, como se presume, dizem respeito a questões internas (como as condutas sistemáticas do cientista em seus atos experimentais e linguísticos, as relações entre hipótese e teoria, e entre indução e generalização, p.ex.), mas também externas (como os condicionantes de ordem política e sociocultural, os quais podem dirigir as posturas seletivas predominantes na comunidade científica, em dada conjuntura; além da consideração da falibilidade e do caráter evolutivo/autocorretivo da ciência) (McCOMAS, 2002; MOURA, 2014). Entre os geógrafos brasileiros (sejam os pesquisadores que estudam a história e a teoria da Geografia, sejam os especialistas em ensino, particularmente), a expressão NdC e a literatura respectiva são ignoradas. Isso se deve, ao menos em parte, ao fato de predominar entre os latinoamericanos (herdeiros da escola francesa) a ideia de que a Geografia é uma disciplina mais próxima à família das Ciências Humanas, visão que, a nosso juízo, acaba segregando toda uma outra faceta que, na realidade, determina a natureza híbrida do campo geográfico (o qual, desde logo, deveria ser visto então como situado em domínio de fronteira, junto a demais ciências socioambientais). Por conseguinte, também acaba predominando entre aqueles, o tácito entendimento de que uma análise filosófica da Geografia deverá seguir o modelo de uma epistemologia das ciências sociais ou das humanidades, o que nos parece equivocado, ou no mínimo reducionista. Daí os epistemólogos da Geografia tenderem a frisar questões tais como contexto ideológico e discurso, ressaltando, pois, o caráter essencialmente histórico do significado da Geografia (tendências que são compartidas com as disciplinas sociais), ou ainda, preocuparem-se com os critérios que definem as escalas espaciais de interesse do geógrafo, bem como com as modalidades de representação iconográfica das informações espaciais - estes sendo, por sua vez, tópicos já bastante inerentes à teoria da ciência geográfica (STASZAK, 2001).
} 
a desenhar um projeto de pesquisa que ao menos jogasse o papel de alertar para a omissão de questões epistemológicas (transgeográficas) na literatura sobre Ensino de Geografia. Parecera-nos que a pesquisa poderia cumprir uma função modesta, mas relevante: frisar a necessidade de uma solidificação teórica da formação dos licenciandos em Geografia.

A pesquisa se inseria na interface dos estudos de filosofia e ensino de ciências, domínio investigativo híbrido, rico, porém subexplorado para a análise do caso ciência geográfica.

\section{Os objetivos e a hipótese da pesquisa}

A pesquisa objetivou o diagnóstico sobre o estado atual do campo do Ensino de Geografia, no que se refere ao temário prevalecente na respectiva literatura: se esse temário incorpora ou não questões-chave da teoria do conhecimento científico. A hipótese que nos guiou foi a de que esses documentos encontram-se rarefeitos de conteúdos epistemológicos genéricos - imprescindíveis, nos parece, para tratar a natureza da ciência, em suas características internalistas e externalistas.

Bastante otimistas e inspirados nas publicações de Adúriz-Bravo - p. ex., quando o pesquisador argentino trata do que chama unidades didáticas (ADÚRIZ-BRAVO, 2007) -, quisemos que o diagnóstico pudesse, ademais, motivar futuras estruturações análogas, a fim de engendrar também para o caso Geografia um ensino de $\mathrm{NdC}$.

Nossa pesquisa pressupôs as seguintes ações coordenadas: (1) destacar da literatura de interface Didática da Ciência - Filosofia da Ciência o que autores especialistas parecem sustentar como tópicos fundamentais de um estudo do tipo epistemológico (estudo visando o entendimento - e daí a transposição escolar - dos aspectos estruturais e dinâmicos da ciência); (2) identificar em manual de Epistemologia da Geografia (de difundido uso) a possível ocorrência daqueles tópicos; (3) examinar amostra de manuais didáticos brasileiros, vigentes no ensino escolar de Geografia (Ensino Médio), buscando, no conteúdo destes, tipos predominantes de tema e de tendência discursa; e, (4) examinar amostra de livros acadêmicos brasileiros, empregados por estudantes de licenciatura e pesquisadores na área de Ensino de Geografia, buscando a mesma espécie de predominância ${ }^{4}$.

\section{Os materiais e o procedimento analítico}

Numa primeira fase, vistoriamos e catalogamos um conjunto de documentos de conteúdo potencial (livros e artigos tratando de filosofia e ensino de ciências, e de epistemologia e ensino de Geografia). Na fase imediata, já de inspeções detidas, empreendemos uma análise de conteúdos e um exercício de extração de passagens textuais demonstrativas das informações buscadas, caso a caso: tópicos fundamentais de Filosofia da Ciência, por exemplo, a ver com a

\footnotetext{
${ }^{4}$ Por esses dois últimos objetivos, quisemos diagnosticar a carga (significativa ou latente/subexplorada) de conteúdos de NdC.
} 
elucidação dos aspectos tanto conceituais, quanto contextuais da atividade científica (LORENZANO, 2011); questões fundamentais de Didática de Ciência, como as relacionadas à abordagem escolar do caráter histórico da ciência, as conjunturas em que se originam e se propagam as teorias (MOURA, 2014); ideias-chave caracterizadoras do pensamento e da prática da ciência geográfica, como, por exemplo, as suas tradições descritivas (CLAVAL, 2011); e quadro de temas e discursos em Ensino de Geografia, como a função sociocrítica do conhecimento geográfico (CAVALCANTI, 2013).

Deliberamos que o registro de extratos se justificaria toda vez que demonstrassem: (1) questões essenciais para uma discussão sobre $\mathrm{NdC}$ (tópicos internalistas, sobre lógica estrutural, e externalistas, sobre forças-motrizes socioeconômicas); (2) características atribuídas ao pensamento geográfico e sua evolução; e, (3) indícios presentes no discurso de geógrafos especializados em Ensino (sinais indicadores de tendências teórico-filosóficas).

Numa terceira etapa, de sistematizações, procuramos coordenar os dados segundo um juízo de implicação (dado-conjectura), de modo a promover as devidas interpretações confirmatórias ou refutadoras da hipótese-guia. E o banco de dados resultante nos habilitava certos exercícios inferenciais: a fraca correspondência (que apenas presumíamos) entre os tópicoschave de Filosofia da Ciência e as matérias tratadas pela Epistemologia da Geografia, e a não correspondência (que também apenas supúnhamos) entre as preocupações temáticas em Didática da Ciência e Ensino de Geografia.

Foram sistematizadas em quadros sinópticos duas das ordens de dados previstas: a que se relacionava com o temário fundamental de Filosofia da Ciência e a que se associava à caracterização dos estudos epistemológicos da Geografia.

\section{Quadro sinóptico 1: sete tópicos-chave em filosofia da ciência}

Conquanto esquemas desse tipo sejam, por natureza, reducionistas, prestam-se bem como uma espécie de guia paramétrico para a exploração didática das questões que constarão ali como elementos essenciais. Apenas devendo, posteriormente, ser problematizadas de modo crítico.

Influenciado pela ideia de tenets presente na produção de autores tais como McComas (2002), Adúriz-Bravo (2007) aprimorou um conjunto de tópicos pelos quais viabilizar uma abordagem sobre $\mathrm{NdC}$ em ambiente escolar. "Critérios estruturantes" que unem, coerentemente, as ideias fundamentais outorgantes da identidade dos campos de estudo - e que já haviam sido esboçados por Adúriz-Bravo, Izquierdo-Aymerich e Estany (2002).

Eles seriam sete: Correspondência e racionalidade: aproximação com que os esquemas explicativos conseguem descrever os fatos do mundo, e confiança nos critérios lógicos da ciência; Representação e linguagens: estratégias lógico-simbólicas que, traduzindo a natureza das relações fenomênicas, permitem a intercomunicação de seus usuários; Intervenção e metodologias: modalidades de ação projetadas antecipadamente, a fim de executar capturas de dados sobre o mundo; Contextos e valores: influência das conjunturas econômica e política, e condicionamento das ações do cientista e dos imaginários sobre ciência, segundo concepções cultural e temporalmente situadas; Evolução e julgamento: mudanças no conhecimento científico em termos de conteúdo teórico e parâmetros de relevância, e apreciação dos ganhos obtidos com elas, de acordo com atuais critérios para estimar a validade das explicações; Demarcação e estrutura: definição dos 
elementos distintivos da ciência, esclarecendo o modo peculiar como esse domínio intelectual organiza suas práticas, por conseguinte contrastando-o com outras formas de conhecimento; e, Normatividade e recursão: princípios canônicos fundamentais que dirigem o trabalho científico, e possibilidade de que posicionamentos teóricos empregados no plano da primeira ordem sejam utilizados e validados, também, no plano da análise metacientífica.

\section{Quadro sinóptico 2: manifestação dos tópicos na epistemologia da geografia}

Uma Epistemologia da Geografia examina as concepções filosóficas subjacentes (e as condições sociológicas combinadas) às práticas de investigação de fenômenos caracterizados por serem organizações espaciais: evolução de formas de relevo, desenvolvimento de regiões industriais etc. Mas a compreensão da natureza científica da Geografia tem de revelar muito mais do que aquilo de que querem tratar os geógrafos; aprimorando a formação intelectual destes, e, mais especialmente o que nos interessa aqui, revigorando a formação de futuros professores desta tão tradicional disciplina - o que poderia nos trazer, como saldo, jovens compreendendo a ciência socioambiental de forma encorpada.

A fim de averiguar o potencial rebatimento de universais de Filosofia da Ciência em obra especialmente geográfica, tomamos como material de análise o livro "Epistemologia da Geografia”, de Paul Claval (2011), célebre geógrafo francês. Posto que se trata de um compêndio bastante popularizado em cursos de graduação brasileiros, ele nos pareceu constituir um excelente documento a partir do qual estimar até que ponto essa literatura autóctone reflete, ela própria, os tópicos de $\mathrm{NdC}$. A seguir, pequena amostra de elementos localizados, e que são possíveis de associar aos tópicos descritos na seção anterior, embora de modo muito indireto:

a) Correspondência e racionalidade: nas pesquisas, geógrafos transformam e refinam, incessantemente, seus procedimentos (p. 16); o raciocínio geográfico é o da orientação, da localização dos fatos observados e suas distribuições, do acúmulo de dados sobre os lugares e o da reflexão em conjunto (p. 51, 56); as "grades de localização" inerentes aos mapas, embora cientificamente elaboradas, não são incompatíveis com as grades de leitura de sociedades tradicionais (p. 59);

b) Representação e linguagens: o geógrafo, em suas pesquisas, indaga, define uma problemática, fixa o alcance das respostas, manobra dentro de um corpus preciso, isto é, executa procedimentos para chegar a um resultado (p. 16); o "mapa" confere legibilidade às anotações de campo (p. 77); o geógrafo tenta restituir, com exatidão, as informações que recolhe, buscando ser fiel à "totalidade" do espaço de que trata (p. 82);

c) Intervenção e metodologias: nos estudos do relevo, faz-se um levantamento minucioso do terreno, vindo a constituir um "sistema científico de localizações" (p. 58); dados geográficos são processados com o objetivo prioritário de encontrar soluções para problemas práticos (p. 82); para chegarem a uma compreensão das "organizações do espaço" na superfície terrestre, os geógrafos procuram entrosar aspectos físicos, biológicos, culturais e históricos (p. 147);

d) Contextos e valores: o geógrafo analisa as distribuições subentendendo que elas assumem determinados significados para os homens que ali se instalam, vivem e percebem (p. $62,65,82)$; logo, a diversidade que ele encontra nos estabelecimentos humanos lhe aponta a necessidade de explicá-la com base nos elementos culturais do costume e dos usos (p. 111); 
no período clássico, os geógrafos estiveram estimulados a descrever cidades, pequenas regiões, mas também países inteiros e seus povos (p. 147);

e) Evolução e julgamento: trabalhos geográficos da primeira metade do século XIX descreviam, principalmente, o espaço rural (p. 65); a produção geográfica mudou conforme descobertas demonstraram ao geógrafo que determinadas formas paisagísticas combinam-se espacialmente (p. 184); novas tendências de pesquisa assumem significados diversos e estimulam práticas distintas para diferentes comunidades de geógrafos (p. 197);

f) Demarcação e estrutura: a ciência geográfica analisa os "encadeamentos" dos quais resultam as múltiplas organizações no mundo, ela não é mera evocação dos lugares, ou uma observação simples, incapaz de distinguir relações de determinação (p. 111); nos estudos de geografia humana, até os anos 1970, o pesquisador tratava das formas de ocupação de modo semelhante a um naturalista, observador e observado eram "compartimentos diferentes do mundo" (p. 219);

g) Normatividade e recursão: os geógrafos guiam, teoricamente, suas observações pelos conceitos de sítio e situação (p. 143); costuma-se exigir que uma epistemologia da Geografia funde-se nos mesmos moldes de uma filosofia da ciência tradicional, naturalista (p. 275).

Como sugerido, no livro de Claval (2011) pode ser constatada, de fato, a presença, ao menos implícita, dos tópicos inerentes aos estudos histórico-filosóficos sobre ciência. Em termos gerais, diríamos que as questões - (1) evolução das teorias geográficas; (2) organização da prática científica do geógrafo; (3) critérios para validação do conhecimento em Geografia; (4) estratégias de representação das formas e dinâmicas paisagísticas sob estudo; e, (5) contextos históricos e socioeconômicos estimulantes das mobilizações em pesquisa geográfica - estão suficientemente visíveis ao longo dos capítulos. Só não podemos afirmar que essas questões sejam realçadas enquanto tal (isto é, enquanto temas que reportam a tópicos-chave de Filosofia da Ciência) quando a obra é explorada nos cursos universitários. De todo modo, não poderíamos dizer que a ideia de epistemologia que Claval (2011) desenha se dissocia da acepção genérica de um "estudo das circunstâncias" que explicam/possibilitam a prática científica. Em seu livro, é perfeitamente identificável a menção às condições em que se encontram, conjuntura a conjuntura, os agentes da ciência geográfica. As inquietudes e dificuldades de época, dos grupos sociais em questão, que foram mobilizando a produção de conhecimento em Geografia. Contudo, dois aspectos restam perturbadores: (1) uma visão epistemológica que privilegia especialmente o ângulo externalista, das "intenções políticas"; e, (2) a baixa referência a autores e textos de Filosofia da Ciência, o que tonifica nossa impressão de que a Epistemologia da Geografia, conservando-se regionalista demais, pode estar desperdiçando os insights presentes na vasta literatura consagrada à filosofia de outras ciências.

A sequela desse segundo aspecto é evidente: o autor não demonstra ao leitor que alguns dos fatores subjacentes à história dos estudos geográficos são, a bem dizer, replicações de lógicas verificadas na história de toda e qualquer disciplina científica. Isto é, o leitor cai na armadilha de enxergar no caso geográfico, o que lhe parecerão notáveis idiossincrasias, quando não o são, necessariamente. Já o efeito negativo do primeiro aspecto seria este: um leitor levado a se concentrar no ângulo estritamente sociológico da produção do conhecimento, como se, ao longo da história, o personagem geógrafo não tenha estado a empregar, independentemente de conjunturas socioculturais, raciocínios lógicos e sistematizações normativas. 


\section{Resultados e discussões (1): a carga de $\mathrm{NdC}$ em manuais didáticos}

Quisemos testar a hipótese de que essa modalidade de documento (manuais escolares de Geografia, de Ensino Médio) encontra-se pouco carregada de conteúdos de segunda ordem. Foram selecionadas cinco obras de grande difusão, aprovadas pelo Programa Nacional do Livro Didático (PNLD).

Analisamos capítulos a partir de três tipos de ocorrência: (1) conteúdo rarefeito de questões epistemológicas; (2) bastante expressivo em temas de segunda ordem; e, (3) com teor apenas latente. Mas estipulamos que a segunda forma de ocorrência (expressividade) poderia ainda apontar duas situações: (2a) textos veiculando abordagens teóricas e/ou historiográficas proporcionalmente salientes em relação à obra integral; e, (2b) a sinalização de abordagens que, apesar de pouco privilegiadas no todo da obra, são plenas em sua muito breve ocorrência. Já pela condição de latência, nos referimos a capítulos em que os autores, embora não deem realce propriamente à NdC, poderiam fazê-lo com provável boa eficiência. As análises são apresentadas a seguir.

No extenso manual didático de Vesentini (2012), "Geografia: o mundo em transição", questões de segunda ordem são pouco visíveis. No exercício de capturar terminologias afins, eventualmente, verificaram-se os casos das expressões ciência e ciência geográfica, sendo que sua maior ocorrência se encontra onde havíamos intuído de antemão: logo nos capítulos iniciais, com o previsível propósito de operar uma função de prólogo. A sensação de que se trata ali de um preâmbulo obrigatório vem espontânea, como se devesse ser cumprido um protocolo: aludir a algum conteúdo metateórico (mormente, de natureza historiográfica). Os dois primeiros capítulos são de natureza potencialmente epistemológica, todavia, ao longo das cinco páginas em que o autor trata mais diretamente da história da disciplina (e isso se dá sob a forma de uma subseção intitulada "Uma breve história da geografia"), a Geografia em nenhum momento é referida como ciência. O fato, porém, é abrandado pela iniciativa do autor em ressaltar os aspectos, aludidos como específicos, do trabalho do geógrafo, no capítulo dois, intitulado "Divisões da geografia e campos de atuação do geógrafo". Oportunidade também rica para uma abordagem de teor epistemológico, já que poderia favorecer a definição da Geografia como um saber auxiliar à intervenção no mundo. Aplicando nossa grade de leitura, diríamos que esse manual didático apresenta uma expressividade tipo (2b) (traços de Contextos e valores no capítulo um), enquanto que, como latência, o tema interpretação de mapas (capítulo cinco) aponta a potencialidade de uma abordagem sobre Correspondência e racionalidade.

"Geografia: espaço e vivência", de Boligian e Alves (2013), é o manual em que menos notamos temários de NdC. Nem mesmo são visíveis os temas sobre uma específica epistemologia da Geografia. Isso, apesar da locução ciência geográfica ser empregada algumas vezes. E causa estranheza que nem sequer nos capítulos introdutórios - onde é de se esperar que ele se encontre, ainda que de modo superficial - esse temário ocorre. De fato, os autores chegam a associar aspectos técnicos do saber geográfico com fatores sociológicos, e mostram, de alguma forma, que a ciência, em geral, foi importante para o entendimento da sociedade, no decorrer dos séculos. Contudo, no transcurso da obra, não volta a ser encontrada essa conexão fecunda. Classificamos, por isso, o manual didático como rarefeito, embora, no quesito latência, possamos afirmar que o breve ponto consagrado à "evolução dos mapas e da cartografia" (capítulo um) delimita um foco fértil para desenvolver o tópico Evolução e julgamento. Assim como o ponto "os mapas e a linguagem cartográfica” (capítulo dois) habilita-se bem à exploração do tópico Representação e linguagens. 
De autoria de Tamdjian e Mendes (2013), “Geografia: estudos para compreensão do espaço" é o manual em que, para nossa surpresa, a presença de uma abordagem sobre ciência geográfica foi explícita e ampla. Em seção especialmente consagrada à história da Geografia, os autores apresentam a evolução dos significados assumidos pelo campo, desde a época medieval até os dias de hoje, e demonstram como a disciplina jogou papel relevante ao longo de tão variadas conjunturas. É certo que uma menção precisa à Epistemologia (geral) também não está, nesse manual didático, razoavelmente presente. Mas o que, de todo modo, nos atraiu a atenção, foram as dezenas de parágrafos em que, agora sim, de modo explícito, são tratados os câmbios de função e entendimento da Geografia. Por conseguinte, a obra nos figurou como decididamente não rarefeita, e só não a classificaríamos como de conteúdo expressivo de tipo (2a) porque a ocorrência de temas de segunda ordem também se encaixa no padrão de estar localizada restritiva e setorialmente - isto é, como preâmbulo que antecede os assuntos centrais da obra. Mas sua expressividade, de tipo (2b), é intensa e denota dois tópicos-chave: Contextos e valores ("a sociedade e a geografia") e Evolução e julgamento ("a evolução da ciência geográfica"), ambos no capítulo um. E ainda poderíamos ressaltar a potencialidade de uma abordagem sobre Representação e linguagens, em função do tratamento, infelizmente descarregado de conteúdo epistemológico, do ponto "cartografia, um conjunto de técnicas" (capítulo dois).

No quarto manual examinado, "Geografia para o ensino médio", de autoria de Magnoli (2012) - possivelmente o mais popular autor de livros didáticos de Geografia do país -, matérias diretamente apropriadas a um ensino da dimensão científica da disciplina voltam a ser pouco visíveis. A expressão ciência aparece, apenas, uma única vez, referência aos contextos de evolução da Geografia, duas vezes. Por outro lado, localizamos cinco menções suficientemente relacionadas à história da ciência em geral, o que nos parece importante, a fim de que o aluno não elabore imagens separatistas. Mas o manual didático, apesar disso, tem conteúdo epistemológico muitíssimo rarefeito. Salva-se pelo quesito latência, dadas as passagens a respeito da linguagem dos mapas, localizadas nos pontos "linguagem cartográfica" e "cartografia e poder" (ambos no capítulo um), vestígios ocultos dos tópicos Representação e linguagens e Contextos e valores.

Por fim, o quinto manual didático avaliado, "Geografia: ensino médio: parte um", de Moreira e Sene (2014), constitui um material que, próximo ao diagnóstico otimista emitido à obra de Tamdjian e Mendes (2013), possui conteúdo epistemológico explícito e de bastante boa qualidade. Ademais, proporcionalmente à dimensão total do volume, o manual veicula em suas cinco primeiras seções (introdução mais os quatro capítulos sucessivos, integrantes de uma unidade inicial chamada "Fundamentos de cartografia") uma sorte de conteúdos perfeitamente possível de capturar por uma lente de segunda ordem. Sucedendo as duas modestas páginas introdutórias, em que os autores parecem querer apresentar a teoria da Geografia, há outras cinco cujo conteúdo, apesar de sintético, tem a evidente intenção de fazer um mostruário de personagens, conceitos e sistemas de pensamento. Esse literal breve histórico nos impulsionaria, a princípio, a julgar a obra como de conteúdo quase rarefeito. No entanto, nos figurou como mais justo classificá-la como de conteúdo expressivo de tipo (2a), posto que, apesar de ela se dar em poucas páginas, a porção do manual consagrada a questões de segunda ordem (pontos essencialmente associáveis ao tópico-chave Contextos e valores) acaba mostrando-se representativa no todo do volume. Além disso, as páginas subsequentes detêm sinais que nos forçam a ressaltar que o livro tem mesmo claras potencialidades de captura pelo ângulo da Epistemologia. Em especial pela natureza da referida seção "Fundamentos de cartografia", a qual compreende 
capítulos sobre "representações e escalas" e "tecnologias modernas utilizadas"; conteúdos passíveis de tratamento pelos tópicos Correspondência e racionalidade, Representação e linguagens e Intervenção e metodologias.

Nos manuais didáticos examinados, pôde-se perceber que, na maioria das vezes, a assuntos relacionados à Epistemologia da Geografia os autores fazem referência introdutória e indiretamente. Como se soubessem tratar-se de questão relevante, embora não merecedora de destaque sob outras formas ou ao longo dos assuntos geográficos. Desperdiça-se, portanto, a interface que estes podem ter com tópicos de Filosofia da Ciência. Sistemas físicos da Terra, impactos ambientais, conflitos de fronteira etc. Todas questões que poderiam ser retrabalhadas, didaticamente, em consonância com eles.

\section{Resultados e discussões (2): a carga de NdC em livros acadêmicos}

Quisemos testar hipótese análoga nessa modalidade de documento (literatura sobre Ensino de Geografia, de uso universitário): ela também se encontra rarefeita de conteúdos de segunda ordem.

Com base nos livros investigados (CALLAI, 2014; CASTELLAR, 2014; CAVALCANTI, 2013), foi possível detectar trechos de capítulos que exprimem, alguns menos, outros mais, relativa importância àqueles conteúdos, na formação dos professores de Geografia. Exemplificaremos a seguir com alguns casos. Cabe esclarecer antes que, a exemplo do que guiou nossa seleção de manuais didáticos, também nos baseamos, para a amostra de livros acadêmicos, no critério de popularização das obras e seus autores. Nesse caso, os três livros examinados constituem obras bastante difundidas em cursos de Licenciatura em Geografia, além de muito recorridas por jovens pesquisadores no campo do Ensino de Geografia. Igualmente, para a avaliação de seus conteúdos, aplicamos a grade de leitura descrita na seção anterior: rarefação, expressividade e latência.

Na décima oitava edição de sua "Geografia, escola e construção de conhecimentos", Cavalcanti (2013, p. 88) afirma: “[...] formulações científicas são referências básicas para a estruturação de conteúdos da geografia ensinada na escola”. E mesmo páginas antes, no início do primeiro capítulo, um trecho já evidencia a autora perfeitamente consciente da interpenetração dos campos da Epistemologia e da Didática, acabando por insinuar ao leitor que as matérias a serem tratadas no transcurso viriam a receber o suporte da primeira: "As últimas décadas têm sido marcadas por intensos debates no pensamento filosófico e científico [...] As diversas áreas científicas, especialmente as ciências humanas, têm efetuado reflexões e análises para compreender os processos de mudanças [...]" (CAVALCANTI, 2013, p. 15).

Essas e outras manifestações textuais, entretanto, não redundam em que a autora proceda a uma abordagem mais detida de questões metacientíficas - pelo menos devidamente conduzida por literaturas em Filosofia da Ciência e Didática da Ciência, das quais derivariam, por efeito, algum insight útil sobre ensino de NdC. Constata-se, ainda, haver pouca exploração da própria Epistemologia da Geografia. No livro há recurso a autores consagrados, associados à teoria social crítica, como Vygotsky, Foucault e Habermas, mas não a teóricos que substantivam a argumentação sobre as ciências e, mais especialmente, seu ensino. Muito utilizada que é por graduandos e professores de cursos de formação em Geografia, é notável, decerto, nessa obra, 
a presença de terminologias prenhes de sentido - e, desde logo, frutíferas - para fazer licenciandos acessarem os domínios internalista e externalista da teoria da ciência, tais como pensamento científico, ciência geográfica e raciocínio geográfico. Porém, suas manifestações podem ser consideradas fraseológicas, na medida em que aparecem ou com o intuito de apontar que, digamos, há algo de natureza filosófica que pode ser explorado, se quisermos. Ou então, o temário que dá entrada a discussões de segunda ordem - transformações técnicas, visões de mundo etc. - consta no discurso como elemento subjacente aos próprios fenômenos que constituem objetos de investigação da Geografia ou do Ensino. Logo, um temário de primeira ordem.

A obra não tinha qualquer obrigação de dar conta de uma frente de abordagem que, de fato, é muito específica. As questões ali desenvolvidas, de evidente valor à formação de professores, engendram um material que gira em torno da preocupação em fazer pensar o ensino segundo o quadro social da realidade. Ou seja, uma discussão sobre a natureza do mundo, conflituosa, contraditória, de injustiças a serem combatidas, toma o lugar da abordagem da natureza da ciência. Mas se é justamente a ciência que, de certa maneira, estudará esse mundo, não deveria ser espontânea uma abordagem autóctone sobre $\mathrm{NdC}$ ?

A seguir, uma pequena amostra de elementos discursivos localizados na obra de Cavalcanti (2013) e que seriam possíveis de associar a alguns dos tópicos-chave sobre NdC:

a) Correspondência e racionalidade: "processos mentais" (p. 28); "desenvolvimento do raciocínio geográfico" (p. 73); "desenvolvimento da habilidade de orientação, de localização, de representação" (p. 94); "sucessivas aproximações do real estudado" (p. 99); noções de processo, escala, especificidade e identidade (p. 105); "funções psíquicas” (p. 146);

b) Representação e linguagens: "análise do conteúdo das representações” (p. 33); “construção de análises espaciais” (p. 73); “análise das representações dos alunos e professores dos conceitos geográficos" (p. 88); referências são construídas com base em habilidades espaciais (p. 95); "confronto das representações do sujeito e do conhecimento elaborado" (p. 142);

c) Intervenção e metodologias: "registros de observações" (p. 29); "modelar, organizar e modificar materialmente o espaço" (p. 97); “compreender a espacialidade das práticas [...] para poder intervir nelas a partir de convicções" (p. 128); "compreender a geografia das coisas, para poder manipulá-las melhor no cotidiano" (p. 128); "construção e leitura de mapas” (p. 150);

d) Contextos e valores: "lógica do poder, da expansão capitalista" (p. 16); "ruptura da modernidade" (p. 17); "construção histórico-ideológica do conceito de um território" (p. 108); "papel histórico que têm desempenhado as formas de poder exercidas por determinados grupos" (p. 110); “concepções diferenciadas que correspondem a visões filosóficas determinadas” (p. 111); “construção do espaço geográfico pela sociedade, ao longo de sua história” (p. 118); "[geografia como] prática social que ocorre na história cotidiana dos homens" (p. 122); "a capacidade de conhecer o mundo e de nele atuar é uma construção social” (p. 140);

e) Evolução e julgamento: "necessidade de reformular categorias e conceitos para compreender melhor o movimento da sociedade" (p. 16); "socioconstrução de conceitos, análises, atitudes" (p. 116); “antagonismos presentes nas teorias geográficas" (p. 117); a realidade social só pode ser explicada por paradigmas já construídos se estes forem reconstruídos criticamente (p. 119); "as informações e os conceitos geográficos permitem tomadas de decisão" (p. 128);

f) Demarcação e estrutura: "tentativa de superação dessa dicotomia [sociedade e natureza]" (p. 118); a análise geográfica busca compreender a sociedade pelo que ela produziu concretamente no espaço (p. 118); a função da Geografia é formar uma consciência espacial (p. 128). 
Callai (2014) é outra autora muito respeitada na comunidade de geógrafos brasileiros, pela expressividade de sua produção na área de Ensino de Geografia. Decidimos examinar um livro acadêmico recente mas bastante difundido editorialmente, e que foi organizado por essa pesquisadora. "Educação geográfica: reflexão e prática" (CALLAI, 2014) reúne capítulos cujos autores procuram dar contribuições ao debate sobre a formação docente e as metodologias para representação e aprendizagem, com a peculiaridade de frisarem as escalas do lugar (de ensino, de vivências) e do indivíduo (que tem diferentes experiências). Numa seleção de trechos que compõem a apresentação da obra, a organizadora nos sintetiza o viés geral das ideias nela veiculadas:

O contexto em que os alunos e também os professores vivem deve ser considerado percebendo os processos atuais de um mundo complexo e com demandas que são internas e também externas ao lugar. Diante dos avanços acelerados que a contemporaneidade apresenta, altera-se a espacialidade e a percepção da mesma [...] (CALLAI, 2014, p. 21).

Considerando o conhecimento dos alunos a partir de seus conceitos espontâneos e a busca de construção dos conceitos científicos, levando em conta o contexto cultural em que se inserem pode-se desencadear o estudo dos conteúdos geográficos. E estes podem contribuir na efetivação de uma aprendizagem significativa, oportunizando o entendimento dos espaços em que vivem no seu viver cotidiano [...] (CALLAI, 2014, p. 24).

A definição de qual conteúdo deve ser ensinado e aprendido em Geografia exige do professor conhecimento da ciência geográfica e da história dessa disciplina escolar. (CALLAI, 2014, p. 32).

A exemplo do livro acadêmico anterior, este contém evidentes indícios de conteúdo latente, que poderia ser capturado por uma lente epistemológica. Todavia, o que parece se dar é uma ação negligente para com essa potencialidade. Também notamos, nos capítulos dessa obra, explícita ausência de recurso à literatura em Filosofia da Ciência e Didática da Ciência, ainda que, para alguns deles, aparentemente, os autores tenham interagido com fontes de significância para uma abordagem metacientífica, como, por exemplo, Bachelard, Bourdieu e Morin. A seguir, amostra dos elementos discursivos potenciais presentes em Callai (2014):

a) Correspondência e racionalidade: a prática cartográfica pressupõe habilidades intelectuais comuns a todos (p. 168); a feitura de mapas pressupõe obediência a critérios padronizados, códigos que estão convencionados (p. 217); desenvolvimento cognitivo e operações mentais (p. 229); o que é o real diante de diversas representações sobre os mesmos espaços? (p. 313);

b) Representação e linguagens: o conhecimento, no plano da comunicação, é um sistema de signos e símbolos (p. 63); importância da mediação para a construção de conhecimento (p. 128); elaboração de desenhos, tabelas, gráficos, mapas (p. 135); mapa como instrumento básico no trabalho do geógrafo (p. 168); o professor deve ter a capacidade de transformar o conhecimento acadêmico que possui em formas de atuação compatíveis com o repertório dos alunos (p. 177); o conteúdo científico escolar deve estar sintonizado com a ciência e a realidade (p. 190); a representação via mapa exige a eleição de símbolos, projeções e escalas (p. 217); 
c) Intervenção e metodologias: saídas de campo, observação, coleta e organização dos dados (p. 80, 193); intencionalidade dos instrumentos (p. 135); mapas habitualmente servem a critérios de planificação e são reducionistas (p. 217); tentativa e erro, elaboração e teste de hipóteses (p. 273); intervenção na realidade baseada num comprometimento ético (p. 277); entrevistas e representações gráficas (croquis, perfis, fotografias) (p. 301);

d) Contextos e valores: "[os espaços] trazem em si as marcas das vidas passadas e as condições de vida atuais" (p. 16); "dimensão cultural do entorno" (p. 20); "cada conteúdo a ser ensinado pode assumir características do lugar em que é trabalhado" (p. 20); "o currículo escolar [...] ao ser resultado de escolhas é ligado a interesses bem determinados” (p. 31); diferentes grupos têm diversas vinculações ideológicas e simbólicas, que se manifestarão em suas concepções de mundo (p. 41); nas instituições escolares encontram-se diferentes experiências, esperanças, desejos e expectativas, logo, é um espaço de múltiplas representações (p. 100); discussões sobre diferença e igualdade, diversidade e inclusão (p. 148); os mapas atendem aos interesses momentâneos dos seus criadores, e os conteúdos são escolhas de pessoas que têm poder de instituir suas representações (p. 223); mapas carregam conteúdo ideológico, veiculam juízos de valor e, portanto, podem revelar estratégias de dominação territorial (p. 242); transformações se dão em diferentes momentos, com base em condições relacionadas às possibilidades técnicas disponíveis e a um jogo conflituoso de interesses (p. 302);

e) Evolução e julgamento: valorização do erro, da dúvida e do caráter provisório do saber (p. 66, 126); necessidade de romper com a base de conhecimento introduzida pela modernidade (p. 122, 139); superação de obstáculos epistemológicos (p. 125); novas apostas teóricas introduziram a concepção de espaço produzido socialmente (p. 154); história da cartografia (p. 243).

Por fim, a terceira obra também reúne várias contribuições e é organizada por uma pesquisadora renomada na área, Castellar (2014). "Educação geográfica: teorias e práticas docentes" nos parecera promissora por pretender tratar dos conhecimentos escolar e científico desde os pontos de vista do professor e do aluno. E por dizer, promover isso mediante uma análise relacional teoria-prática: "pensando epistemologicamente" a origem dos saberes viabilizada por “intervenções educativas" (CASTELLAR, 2014, p. 7). No capítulo assinado por Castellar, encontramos passagens que habilitariam, de fato, explorações metacientíficas:

[...] o conhecimento e a aprendizagem não constituem uma cópia da realidade, mas sim uma construção ativa do sujeito em interação com o entorno sociocultural. (CASTELLAR, 2014, p. 39).

[...] mapas como construções sociais e que transmitem ideias e conceitos sobre o mundo, apesar da pretendida neutralidade e objetividade que os meios técnicos utilizam para confeccioná-los. (CASTELLAR, 2014, p. 47).

Mais uma vez, constata-se pouca exploração da literatura corrente em Didática da Ciência e Filosofia da Ciência/NdC. Os autores demonstram ter se valido de alguns nomes conhecidos, mas os mais amplamente destacados são os de produção em teoria social crítica, como Vygotsky, não em aprendizagem de ciência. Isso, apesar de serem salientadas nos capítulos as epistemologias construtivista, de Piaget, e evolucionista, de Bachelard.

Por fim, apresentamos uma amostra de passagens potencialmente conectáveis a tópicos de NdC em Castellar (2014): 
a) Correspondência e racionalidade: a aprendizagem depende de processos mentais (consciência reflexiva, pensamento abstrato) e interação social (p. 39, 89); “a escala é uma proporção entre o real e o mapa” (p. 46); princípios da Geografia: localização, distribuição, conexão, delimitação e escala (p. 85); raciocínio multiescalar (p. 116); relações topológicas a explorar no ensino escolar de Geografia: proximidade, distância, conjunto (141);

b) Representação e linguagens: "símbolos que representam fenômenos geográficos” (p. 45); elaboração de conceitos a partir da discussão e ampliação do conhecimento prévio dos alunos (p. 47, 68); representação cartográfica e raciocínio analítico (p. 53); nos mapas a diversidade de objetos e a proporcionalidade entre eles são transmitidas por códigos visuais (p. 58); os conceitos servem à comunicação e à solução de problemas (p. 87); os conhecimentos e hipóteses de quaisquer pessoas são relevantes (p. 98); diferentes linguagens (textos, croquis, fotos, mapas) podem operar na representação do espaço geográfico (p. 116, 143);

c) Intervenção e metodologias: "o aluno é um sujeito mentalmente ativo na aquisição de saberes” (p. 39); conhecer é agir e transformar o real (p. 44); mediante situações-problema, o aluno experimenta o caráter processual da construção do conhecimento, bem como as dificuldades inerentes (p. 143);

d) Contextos e valores: mapas são práticas históricas, revelam visões de mundo (p. 52); escolha de conteúdos de relevância sociopolítica (p. 74); instrumentos e significados, por possuírem uma ancoragem contextual, ao serem apropriados pelo sujeito este reproduz formas histórico-sociais (p. 98, 119); imagens caricaturais da ciência e do cientista (p. 99); a supremacia contextual de certas escolas de pensamento influencia a formação docente, podendo derivar daí lacunas de conhecimento que estas escolas não preenchem (p. 134);

e) Evolução ejulgamento: evolução da cartografia e avanço contínuo do raciocínio abstrato (p. 52); formação continuada dos professores para habilitá-los à demonstração, aos alunos, dos aspectos psicológicos envolvidos nas experiências de obstáculo e superação científica (p. 114, $117)$

f) Demarcação e estrutura: estrutura lógica da ciência define sua peculiar forma de reflexão sobre o real (p. 79).

Os três livros acadêmicos examinados terminam autorizando um diagnóstico convergente: há elementos latentes, subexplorados, que possibilitariam tratar de $\mathrm{NdC}$ também na literatura geográfica. São, contudo, dispensados (porque, talvez, nem sequer cogitados) os préstimos de teorias metacientíficas robustas, que contribuiriam a uma radiografia epistemológica dos conceitos e das práticas do geógrafo. Aspectos que, constituindo a natureza da ciência geográfica, deveriam (com bastante serventia) ser transpostos para as salas de aula.

\section{Considerações finais}

A investigação, que constituiu projeto de pesquisa para a iniciação científica de alunos da Universidade de Brasília, teve por propósito a identificação de tendências temáticas e discursivas, predominantes na literatura brasileira sobre Ensino de Geografia. Literatura esta que organizamos em duas classes: livros concebidos para o público acadêmico e manuais didáticos elaborados para o público escolar. Nos primeiros, impera o argumento de que tirar partido das experiências do aluno, como sua própria localização no espaço concreto e vivido, por exemplo, 
constituiu uma modalidade ideal de aprendizagem. E essa retórica anima, há muito tempo, o seio da comunidade de pesquisadores em Ensino de Geografia, no Brasil. Enquanto nos segundos, a necessidade de abranger a maior variedade possível de assuntos recomendados pelas diretrizes governamentais, determina mesmo uma fatal predominância de temas de primeira ordem.

Cabe destacar que, nos manuais didáticos para Ensino Médio, acaba sendo previsível constatar-se alta preponderância de abordagens do temário atinente à chamada geografia bumana. Porque os fenômenos naturalistas, como formas e processos de ordem físico-ambiental, têm sido ensinados, principalmente, no Ensino Fundamental. Todavia, pensamos que esse fato acabou conferindo à nossa amostra um papel revelador. Pois, considerando-se que os autores tinham, então, o compromisso de tratar de temas que dizem respeito a dinâmicas espaciais econômicas, geopolíticas e culturais (primeira ordem), esperamos que suas obras pudessem nos apontar um conteúdo sensível, também, aos condicionantes sociológicos da própria constituição dos conhecimentos tratados ali, ao longo das páginas (segunda ordem). E isso não foi verificado! Mas, como se travam de manuais com claro corte sociológico, não poderíamos esperar que uma abordagem da disciplina nesse viés fosse facilitada mediante o recurso aos aspectos contextuais, também humanos, subjacentes aos próprios conteúdos tratados?

Nos manuais, quando assuntos potencialmente associáveis à $\mathrm{NdC}$ aparecem, eles estão num só capítulo, em geral introdutório, e não ressurgem nos momentos posteriores da obra. Nesses capítulos de abertura, fazem-se menções a personagens da Geografia e às características gerais da disciplina. Contudo, convém termos claro: isso não quer dizer que os docentes, autonomamente, os explorem de fato em sala de aula. Talvez até o mais provável seja que os saltem, dado o exíguo tempo para tratar a vastidão de temas, entendidos como mais importantes, posto que são tópicos cobrados em exames pré-universitários.

A avaliação dos livros acadêmicos, por sua vez, mostrou-nos que não há propriamente deficiência em conteúdos epistemológicos aptos a promover um tratamento sobre natureza da ciência. O que ocorre, porém, é que muitos capítulos são devotados a uma preocupação e a um discurso tornados paradigmáticos nas últimas décadas. Valorização do espaço de vida cotidiano dos alunos e um espírito denunciador de desigualdades. É certo que o relevo dado ao cotidiano e à natureza injusta do mundo contemporâneo tem sua importância, mas, se atrelado às discussões de $\mathrm{NdC}$, não pode ser operado um mais consistente esclarecimento das questões e imaginários, alguns claramente superficiais? Há trechos em que se detecta excelente oportunidade de dar relevo à Filosofia da Ciência e, por aí, fazer com que os leitores, futuros docentes, adquiram uma mirada mais densa a respeito da natureza dos conteúdos. E o pensamento imerso em alguns dos textos se restringe a um olhar lançado à ambientação do ensino, digamos assim, não empreendendo correlações com o que está por trás do aparato linguístico e instrumental de que o ensino de Geografia precisa se servir.

Mas reconhecemos que nossa hipótese-guia, de enunciação algo pessimista, originalmente, terminou apenas parcialmente verificada em ambas as modalidades de documento textual. Embora, de fato, não estejam tão evidentes conteúdos de segunda ordem quanto se poderia desejar, surpreendeu-nos que alguns dos textos examinados apresentavam espécies de informação que, conquanto em estado subexplorado, poderiam constituir germens a partir dos quais desdobrar enquadramentos filosóficos e históricos. Logo, boas explanações sobre NdC.

Destacaríamos, aliás, um assunto fértil, muito presente nas obras: a cartografia. Tão associado à imagem dos geógrafos, tal instrumento de representação de dados espaciais, o mapa 
seria, por excelência, um ensejo riquíssimo para fazer incidir a reflexão epistemológica sob o ângulo especialmente lógico-analítico do raciocínio, das inferências. Importante frisar ao estudante de Licenciatura que ele está lidando com um artefato que, mais além de ser empregado para traduzir, semiológica e abstratamente, a magnitude e a distribuição espacial de fenômenos, também expressa a natureza cientifica da disciplina que escolheram lecionar. Disciplina que possui, via mapa, uma notável identidade linguística e operacional. Ou seja, se é verdade que os mapas colocam a possibilidade de uma discussão histórico-sociológica, já que, como as próprias autoras salientam, sua confecção sempre esteve associada a demandas políticas, bem como a visões de mundo particulares, também é certo que os códigos semióticos, sobre os quais se estruturam, evocam a dimensão lógico-normativa da prática científica - geográfica, no caso. O fato interpõe, portanto, uma fecunda entrada à Filosofia da Ciência. Mas a cartografia é, na verdade, só mais um exemplo de como ainda não percebemos, no ensino de Geografia, que alguns de nossos assuntos mais icônicos, como o determinismo ambiental, as interações sociedade-natureza, etc., poderiam ser ricos e facilmente tratados pela lente epistemológica.

Pensamos que uma pesquisa futura junto a programas curriculares de cursos de Geografia poderá nos revelar outras dimensões do problema. Sobretudo em um contexto em que se aventa a possibilidade de tornar facultativa a aprendizagem de saberes geográficos no Ensino Médio. Por ora, intuimos que, apesar do interesse que possa haver pela história da ciência geográfica nos bacharelados da área, e por assuntos gerais de didática, nas licenciaturas, isso não tem redundado, obrigatoriamente, em discussões gerais sobre ciência no âmbito da primeira habilitação, ou sobre ensino de ciência no da segunda. Noutras palavras, mesmo quando programas de Bacharelado em Geografia tocam, de algum modo, nos aspectos filosóficos da disciplina, eles raramente o fazem recorrendo ao campo da Filosofia da Ciência, o que, a nosso juízo, deveria acontecer naturalmente, se é importante sustentar o estatuto científico da Geografia. E, mesmo quando programas de Licenciatura em Geografia cumprem, de certa maneira, o compromisso com matérias pedagógicas, pode-se estimar que se resumam a reflexões sobre didática da Geografia; desconsiderando a necessidade de chegar até elas, passando, antes, pelas discussões sobre didática da ciência, o que nos pareceria crucial, a fim de que os licenciandos, futuros professores de Geografia, não caiam na armadilha de enxergar a disciplina como uma entidade autossuficiente.

Se presentes na formação de professores, os estímulos a uma reflexão acerca da natureza da ciência poderão resultar em futuras práticas docentes elas mesmas estimulantes, replicadoras, pois, de um pensamento crítico e filosófico, o que levaria os jovens a compreenderem não apenas os fenômenos manifestos no espaço geográfico, mas, de forma encorpada teoricamente, os próprios fatores envolvidos na interpretação científica dos mesmos.

\section{Agradecimentos}

Os autores agradecem ao Conselho Nacional de Desenvolvimento Científico e Tecnológico (CNPq) pela concessão de bolsa de Iniciação Científica a uma das alunas envolvidas no projeto. 
"Natureza da ciência geográfica": diagnóstico e possibilidades ...

\section{Referências}

ADÚRIZ-BRAVO, A. A proposal to teach the nature of science (NOS) to science teachers: the "structuring theoretical fields" of NOS. Review of Science, Mathematics and ICT Education, Athens, v. 1, n. 2, p. 41-56, 2007. Disponível em: < http://resmicte.lis.upatras.gr/ index.php/review/article/view/109/239>. Acesso em: 30 jan. 2018.

ADÚRIZ-BRAVO, A.; IZQUIERDO-AYMERICH, M.; ESTANY, A. Una propuesta para estructurar la enseñanza de la filosofía de la ciencia para el profesorado de ciencias en formación. Enseñanza de las Ciencias, Barcelona, v. 20, n. 3, p. 465-476, 2002. Disponível em: <http://www.raco.cat/index.php/Ensenanza/article/view/21839/21673>. Acesso em: 30 jan. 2018.

AMADOR-RODRÍGUEZ, R. Y.; ADÚRIZ-BRAVO, A. Consensos y disensos en torno al concepto de naturaleza de la ciencia (nos) en la comunidad iberoamericana de didáctica de las ciencias. Revista Científica, Bogotá, v. 1, n. 15, p. 30-46, 2012. Disponível em: <https:// revistas.udistrital.edu.co/ojs/index.php/revcie/article/view/3936/5644>. Acesso em: 30 jan. 2018.

BOLIGIAN, L.; ALVES, A. Geografia: espaço e vivência: ensino médio: volume único. 3. ed. São Paulo: Atual, 2013.

CALLAI, H. C. Apresentação. In: . (Org.). Educação geográfica: reflexão e prática. Ijuí: Ed. Unijuí, 2014. p. 15-33.

CASTELLAR, S. A psicologia genética e a aprendizagem no ensino de geografia. In:

(Org.) Educação geográfica: teorias e práticas docentes. 3. ed. São Paulo: Contexto, 2014. p. 38-50.

CAVALCANTI, L. S. Geografia, escola e construção de conhecimentos. 18. ed. Campinas: Papirus, 2013.

CLAVAL, P. Epistemologia da geografia. Florianópolis: UFSC, 2011.

LORENZANO, P. La teorización filosófica sobre la ciencia en el siglo XX (y lo que va del XXI). Discusiones Filosóficas, Manizales, v. 12, n. 19, p. 131-154, 2011. Disponível em: <http://www.scielo.org.co/pdf/difil/v12n19/v12n19a07.pdf>. Acesso em: 30 jan. 2018.

MAGNOLI, D. Geografia para o ensino médio: volume único. 2. ed. São Paulo: Atual, 2012.

MATTHEWS, M. R. História, filosofia e ensino de ciências: a tendência atual de reaproximação. Caderno Catarinense de Ensino de Física, Florianópolis, v. 12, n. 3 , p. 164-214, 1995. Disponível em: <https://periodicos.ufsc.br/index.php/fisica/article/ view/7084/6555>. Acesso em: 30 jan. 2018.

McCOMAS, W. The principal elements of the nature of science: dispelling the myths. In: . (Ed.). The nature of science in science education: rationales and strategies. New York: Kluwer, 2002. 
McGUIRE, J.; TUCHANSKA, B. Da ciência descontextualizada à ciência no contexto social e histórico. Revista Brasileira de História da Ciência, Rio de Janeiro, v. 6, n. 2, p. 151-182, 2013.

MOREIRA, J. C.; SENE, E. Geografia: ensino médio: parte 1. São Paulo: Scipione, 2014.

MOURA, B. A. O que é natureza da ciência e qual sua relação com a história e filosofia da ciência? Revista Brasileira de História da Ciência, Rio de Janeiro, v. 7, n. 1, p. 32-46, 2014.

SILVA, F. A. Descoberta versus justificativa: a sociologia e a filosofia do conhecimento científico na primeira metade do século XX. Revista de Teoria da História, Goiânia, v. 1, n. 2, p. 52-67, 2009. Disponível em: <https://www.revistas.ufg.br/teoria/article/ view/28469/15981>. Acesso em: 30 jan. 2018.

STASZAK, J.-F. La géographie. In: BERTHELOT, J.-M. (Dir.). Épistémologie des sciences sociales. Paris: PUF, 2001. p. 77-116.

TAMDJIAN, J. O.; MENDES, I. L. Geografia: estudos para compreensão do espaço. 2. ed. São Paulo: FTD, 2013.

VESENTINI, J. W. Geografia: o mundo em transição: ensino médio: volume único. 3. ed. São Paulo: Ática, 2012. 